\title{
Online teaching research in universities based on blockchain
}

\author{
$\mathrm{Li} \mathrm{Min}^{1}$ (D) $\cdot$ Ge Bin ${ }^{2}$
}

Received: 8 July 2021 / Accepted: 6 January 2022 / Published online: 13 January 2022

(C) The Author(s) 2022

\begin{abstract}
This study explores the use of blockchain in the course design and evaluation in Chinese universities, and explores the value of teachers' views and experiences on blockchain in the course design. Previous studies have shown that blockchain has a positive effect on the improvement of online teaching management and evaluation quality. Most of the current research focuses on the management of online teaching by using blockchain, and this qualitative case study investigates the design and evaluation of online course based on blockchain by five teachers of different specialties. Semi-structured interviews and course materials were collected from five teachers for a TPACK framework analysis. The result of the survey emphasizes that the redesign of online courses based on blockchain can improve the matching between blockchain and courses, the quality of teaching and the trust of various parties in online education. The block chain-based the online course of both theory and practice design and evaluation, which is oriented by the index method of capability evaluation, is an appropriate idea and has achieved good results. The experimental course focuses on the integration of blockchain and experimental platform. The immersive and interactive course presentation and the personalized examination based on machine learning are effective. But follow-up should pay attention to the different requirements of course design of different disciplines, using a variety of data sources for analysis, to take measures to enhance the enthusiasm of teachers to adopt new technologies.
\end{abstract}

Keywords Blockchain · Online teaching · TPACK · Case study

Li Min

lmncee@163.com

1 School of Education, Henan University, Kaifeng 475000, Henan Province, China

2 College of Technology and Communication Kaifeng Henan, Kaifeng 475000, Henan Province, China 


\section{Introduction}

With the development of digitization, network and global learning environment, online teaching, which integrates the Internet, intelligence, technology and transcends the limitation of time and space, has become the new normal of university teaching (Wu, 2020). However, with the spread of online teaching during the epidemic, the content of online teaching is complicated and difficult to supervise, and there are also serious problems such as the loss of privacy and lack of trust in students' learning. Traditional offline instructional design and evaluation methods cannot win students' attention and the recognition of education stakeholders, which seriously restricts the credibility and acceptance of online instruction. The exploration of online teaching has become an urgent problem in the development of pedagogy (Kong et al., 2021). Among them, the use of new technology to reform the teaching of courses has been the focus of educational research (Petersen \& Hossein, 2016). Pierson (2001) took the lead in introducing technical knowledge into the domain of teaching professional knowledge, and initially formed the TPACK framework which integrates the content knowledge of integrated technology (TCK), the pedagogical content knowledge of integrated technology (TPK) and the teaching knowledge of integrated technology (PCK)(Cox \& Graham, 2009). With the popularization of information technology, the application of technology in teaching has become more and more important. From the early production of professional video, the use of drawing software, the live course(Koehler \& Mishra, 2009), to the recent flipped classroom, massive open online course, etc., more and more researches focus on the improvement of teaching level and teaching quality brought by technology (Long et al., 2019; Downes, 2019).

Blockchain is a distributed record or distributed public ledger database. The decentralization, intelligent contract, machine learning and encryption of blockchain can effectively date back to the data, validate the data and encourage each node to perfect the data, and enhance the multi-party trust (Xu 2017). Previous research has shown that blockchain has a positive effect on the improvement of online teaching management and evaluation quality (Don and Alex 2016; Raimundo \& Rosário, 2021). The blockchain carries on the massive research in the university management (Li and Zhang 2017). However, there are few researches on the concrete course design and evaluation. This research takes the online course as the research object, discusses the design and implementation method of the online course adapted to the blockchain, and the influence of the teachers' opinions and viewpoints on the online course design and evaluation, in order to get better online teaching effect.

\section{Literature review}

\subsection{Technological pedagogical content knowledge (TPACK)}

Teachers are the basic force of education development. The knowledge structure of teachers has a direct impact on teaching quality (King et al., 2019; Li et al. 
2017). The teaching knowledge of traditional teacher mainly includes the content knowledge (CK) and the pedagogy knowledge (PK). Shulman (1986) introduced the concept of PCK (Pedagogical Content Knowledge) when he analyzed the knowledge structure that teachers should have. He believes that PCK is the intersection of content knowledge and pedagogy knowledge and is independent of them. PCK is based on the condition that teachers choose appropriate teaching methods to enable students to better grasp the knowledge according to different course content. This idea of teaching for students' learning is also supported by the National Science Teachers Association and the National Council for Accreditation of Educator Preparation. With the advent of the information age, the way of teaching and learning has changed, and technology, especially information technology, is playing a more and more important role in teaching. Pierson (2001) pioneered the introduction of technical knowledge into the teaching profession. In 2005, Niess (2011) introduced technology into PCK model and considered technology as an integral part of teaching. In 2006, Koehler and Mishra defined the pedagogical content of the TPCK. In 2007, Thompson and Mishra officially renamed TPCK to TPACK. The American Association of Colleges for Teacher Education publishes Handbook of Technological Pedagogical Contet Knowledge for Educators.

Studies have shown that, teachers' working ability, working attitude, provided learning resources and teaching methods were significantly correlated with students' online teaching satisfaction (Wang et al. 2020). Teachers' experience and perception of technological innovation in the classroom is an important factor in determining whether they use or continue to use technology (Spotts, 1999). In addition, teachers' perspectives may have a direct impact on students' behavior and learning outcomes when using innovative technologies in the classroom (Churchill and Churchill, 2008). Understanding Teachers' experiences and perceptions related to technological innovation is therefore critical to increasing the use of such innovation (Churchill and Churchill, 2008). Therefore, this research takes TPACK as the research frame, through investigating the higher education teachers' experience and view to blockchain, analyzes the influence of teachers' attitude to technology on the course design and evaluation based on technology to accumulate some experience for the blockchain and other technologies based on the course design and evaluation.

Figure 1 summarizes the four sources of teaching knowledge structure: the technological content knowledge (TCK), the technological pedagogy knowledge (TPK), the pedagogical content knowledge (PCK) and the technological pedagogical content knowledge (TPACK)(Graham, 2011) Fig. 2 .

\subsection{Research on blockchain in higher education}

In recent years, the blockchain-based online teaching of higher education has exploded (Chen et al., 2018). The design and evaluation of online teaching in higher education based on blockchain is a mechanism to rebuild trust, which helps to build trust among education stakeholders, and its improvement on the service supply 


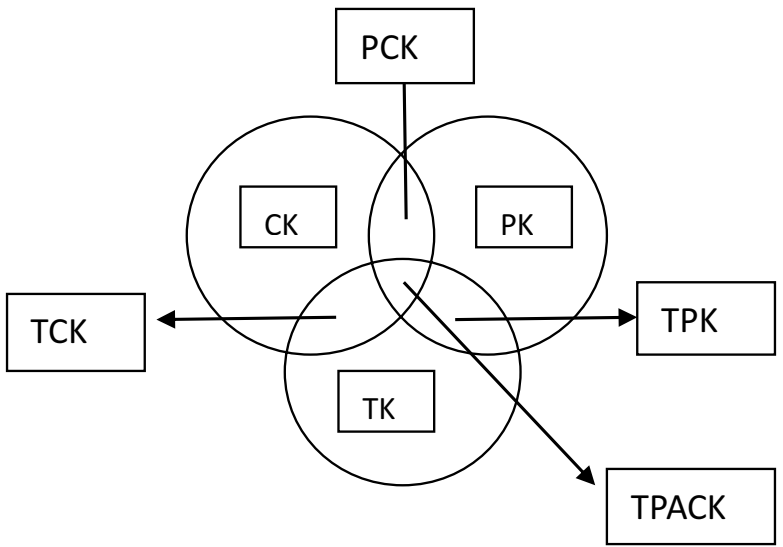

Fig. 1 TPACK Framework

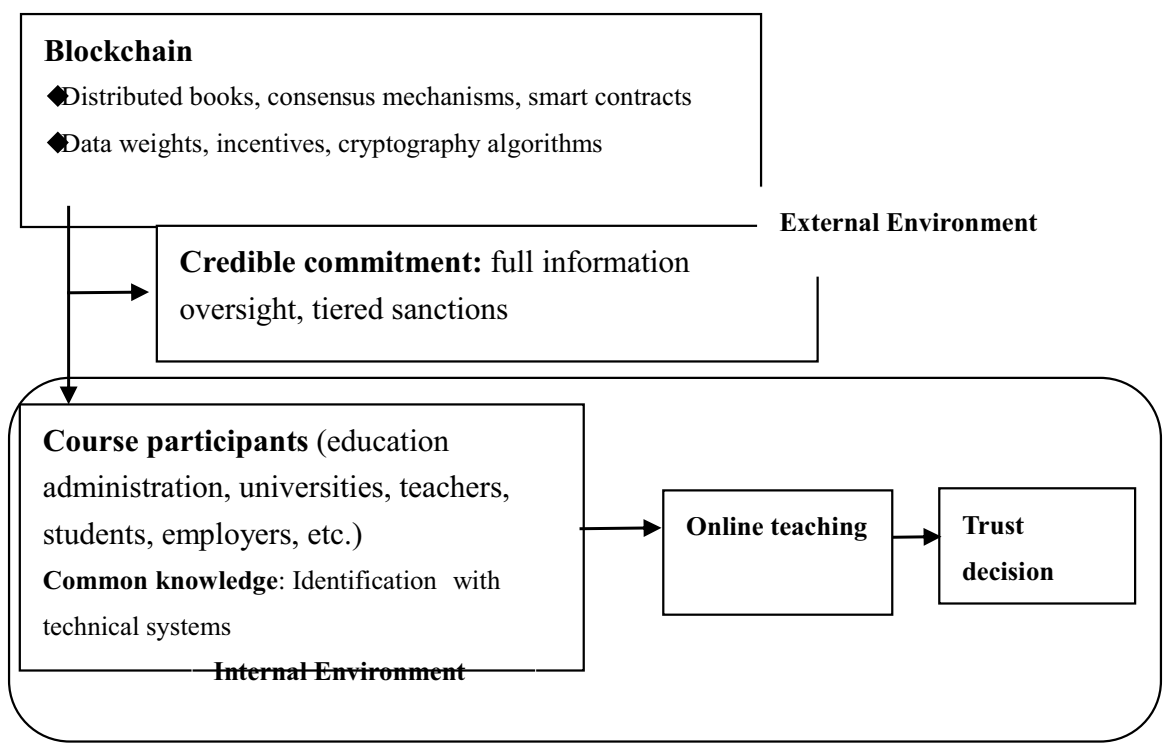

Fig. 2 System Trust of Online Teaching Based on Blockchain

model of digital educational resources, such as blockchain transcripts (Huang 2021), resource management of learners (Pablo and Carles, 2019), and learning books (Merija and Janis, 2018) also helps to improve the complexity of online content, which is not easy to monitor, the difficulty to record, analyze and evaluate students' learning, state and ability to achieve the degree of deficiency of the traditional education model (Mentzer et al., 2020), thus enhancing the credibility and sustainability of online teaching (Lizcano et al., 2020). 
The research and practice of blockchain in the field of higher education mainly focus on three aspects.

\section{a Technical development of blockchain}

The first is the education of blockchain technology. Since 2016, the University of California, Berkeley, has launched a blockchain undergraduate program, while Stanford and the Massachusetts Institute of Technology have all launched blockchain courses. The University of Nicosia in Cyprus has taken a bold step towards a master's degree programme in blockchain technology. Draper University, the University of Cumbria, the University of Nicosia and others accept digital currency tuition (Fedorova \& Skobleva, 2020). In 2016, China's Tsinghua University began a blockchain-related course, named Cognitive Foundation beyond Disciplines. In May 2018, Tsinghua University established the national university blockchain education alliance-the Ivy League, and released the first innovation experimental platform based on blockchain -Ivy Chain, with the aim of training talents of blockchain for the university.

\section{b Application of blockchain in education}

The second is the convergence of blockchain and other technologies. In the process of development, blockchain and other technologies continue to integrate, trying to find a suitable research method for the course design such as the integration of blockchain and machine learning (Wang and Qiao, 2020), the combination of blockchain and genetic algorithm to build an English test platform (Wu 2020) and the combination of blockchain and Business Model Canvas to build an intelligent blockchain courses (Oganda 2020).Blockchain promotes the course design In the existing research, bioinformatics database (Chen, 2019), English teaching (Wang and Qiao, 2020), engineering education and other courses have been combined with blockchain technology. The Bioinformatics Database Course emphasizes the rights of data and the ability of machine learning at the age of big data, and emphasizes the ontologies as the core of the course. English teaching emphasizes the combination of blockchain and the virtual platform to enable students to gain immersive learning experience and enhance learning effect. The curriculum of engineering education uses the capacity-output-oriented idea in the Washington Accord to design the curriculum by using the blockchain. The EU funded research project QualiChain aims to strengthen the link between education and the labour market through new technologies. The project combines blockchain with data analysis and decision support techniques to design and optimize the course flow for students in the School of Electrical and Computer Engineering at the National Technical University of Athens, and enhances students' ability to acquire the skills needed by the market (Kontzinos et al. 2020). Blockchain provides a new perspective and method for the curriculum design.Blockchain expands service supply mode of digital educational resources The existing research mainly includes the blockchain design of course learning, the construction of classroom ecosystem, the blockchain report card, the learner resource management, the study account book and so on (Xia and Xu, 2020; Milovich et al., 2020; King et al., 2019). Distributed course certification authorities add certificate data to the blockchain as a permanent and immutable public record, and Sony Global Educa- 
tion has announced the development of a new blockchain for storing learning and award-winning certificate records (Downes, 2019). In 2016 MIT and a company launched Blockcerts, a digital certificate system based on the blockchain. The system was later used to issue digital certificates for the participants in MIT global entrepreneurship training camp in Seoul, South Korea, and to create digital certificates recorded on the blockchain for some undergraduates, master and doctoral graduates. China's Central University of Finance and Economics and Microsoft have teamed up to create a program named Campus Blockchain that will lower the cost of schooling, job hunting and hiring by creating a convenient and trusted certification system, thereby promoting open education and credibility.Blockchain enhances management capabilities to higher education In March 2018, Oxford University academics launched the first blockchain-based university, Woolf University, using apps to build courses and teach, allowing students to earn full credits and earn a department for the education degree. Tuition is paid in digital currency, the proceeds go mainly to teachers, administrative costs are very low, and the student learning process, agreement management, tuition collection and payment management, as well as a student academic performance are all recorded by blockchain (Xia and Xu, 2020). Later, some scholars also put forward a blockchain-based lifelong learning platform, such as blockchain technology to digital educational resources circulation and sharing platform (Aslan and Ataşen, 2020) and content platform, the innovative application of the continuing education platform(Karatas, 2018),open education resources (OER) new ecological construction(Li \& Yang, 2018).Learning process, evaluation and achievements in the platform are objective and traceable, which ensures the reliability of learning process to a great extent, and enhancing society's trust in online learning.

\section{c Reflecting on the application of blockchain}

Firstly, How to ensure the security of blockchain as a technology?(Moubarak et al. 2018) The blockchain gains the trust of the system by ensuring the security of data, such as decentralization, openness and autonomy. However, there are still some deficiencies in the basic technology of blockchain, such as the adoption of international cryptographic algorithms, intelligent contracts and so on, which is not completely autonomous and increase the risk of being attacked. More than $51 \%$ of the computing power can rewrite the blockchain data. Although the possibility is small, the education data is huge, detailed, important, and it still should be cautious. Secondly, Blockchain is in the location between traditional centralized information governance and decentralized information governance. (Lemieux et al. 2020)While managers are aware of the significant opportunities for distributed, decentralized education in terms of efficiency and new ways of teaching, blockchain technology cannot be applied to all aspects of education, and some scholars put forward a new analysis framework of strategic information governance, and think that the hybrid system, that is, the partial decentralization system, will be more suitable to the challenges of the transition period.

As can be seen from the above, Although there are many researches on education and curriculum design of blockchain, the research on applying blockchain to curriculum design is limited, and the research on different types of curriculum design based on blockchain is even less. This study is based on the analysis of 
the experiences and opinions of five college teachers who use blockchain in the course design and evaluation, and provides some explorations for the future use of blockchain-based online teaching course design and evaluation.

\section{Research design}

This research uses the method of qualitative case study to record the situation of online course design and evaluation of five university teachers based on blockchain. The qualitative case study approach enables researchers to conduct in-depth analyses to gain a comprehensive understanding of all aspects of the study and to gain a holistic and comprehensive understanding of the study (Punch, 2005). The study analyzed teachers' responses to blockchain-based online course design and evaluation and mainly solves two problems:

1. 1 their teaching design based on blockchain and implementation

1. 2 successful completion of the online course teaching based on blockchain

\subsection{Contexts and participants}

Purposeful sampling was used in this study. This study uses targeted sampling to fully engage teachers who are able and willing to share their experiences and perspectives on the exploratory use of blockchain-based online course design and evaluation(Patton, 2002).

The study was conducted online for juniors at key universities in a central Chinese province. Five teachers participated in the study. The two researchers, who are also teachers at the uniersity, have a better understanding of the teaching process and facilitate communication, but are not affiliated with the participants. All five teachers conducted blockchain-based courses during the outbreak. The five teachers had different classes. Teacher 1 teaches Telecommunications Engineering in the College of Physics, teacher 2 teaches Human Resource Management in the College of Management, and teacher 3 teaches Chinese language and literature. Teacher 4 teaches Natural Resources and teacher 5 teaches Experimental Psychology.The five teachers were recruited for the study for two reasons. First, they were active, communicative and sharing teachers. This helps researchers to obtain sufficient information of curriculum design, to explore and analyze more in-depth. Second, the courses they teach cover the traditional combination of engineering, science, liberal arts, and experimental courses. Among them, Communication Engineering belongs to engineering, Natural Resources and Experimental Psychology to science, Chinese language and literature to arts, while Human Resource Management belongs to both arts and sciences. The five courses participate in the blockchain of online course design and evaluation of the study with a strong representation and a wide range. Third, all five teachers have a technical background. The 36-year-old teacher who teaches telecommunications engineering with a background in science and engineering has some knowledge of blockchain and information technology; the 43-year-old 
management teacher who won a bid for a national blockchain project; and the 56-year-old Chinese language and literature teacher, who is willing to explore new technology, has volunteered to participate in the school's blockchain training. The professor of natural resources, 41, Ph. D., has strong computer skills and participates in the blockchain training program; the teacher of experimental psychology, 54, $\mathrm{Ph}$. D., professor, was a visiting scholar at Harvard for a year, concerned with advanced technology, and participated in blockchain training program. They also have more than 10 years of teaching experience. The personal data of the five participants is provided in Table 1.

These five teachers have participated in the school blockchain training, and the blockchain training is divided into two parts. The first part is the course or the lecture form carries on the instruction of theory. The second part is a discussion among teachers on how to improve the practical application of blockchain.

\subsection{Data collection}

Data collection mainly comes from two aspects: one is the semi-structured interview between the researcher and the interviewees. The interview is divided into two stages. The first stage is the beginning of the semester before the start of the course. The average interview time with each interviewee is about $40 \mathrm{~min}$. The interview included: What do you know about blockchain? Do you think blockchain application in online course design can improve teaching quality? If you think you can improve the quality of your online education, what can you do to improve it? What are the main difficulties in designing blockchain-based online courses? (See Appendix 1 for detailed questions). The second stage is the end of the semester after the course. The average interview time with each interviewee is about $80 \mathrm{~min}$. The interview included: How do you design and evaluate online courses based on blockchain? What adjustments have you made? What do you think are the main advantages of blockchain-based online course design and evaluation? Do you think the learning and application of blockchain has improved your blockchain level and helped your teaching ability? What are your suggestions for future research on blockchain-based course design? (See Appendix 2 for detailed questions). Interview data are recorded and transcribed, and reviewed by members to improve effectiveness (Merriam, 2009; Punch, 2005).

Table 1 Summary of the participants

\begin{tabular}{lllll}
\hline Code & Gender & Subject field & $\begin{array}{l}\text { Teaching } \\
\text { experiences(years) }\end{array}$ & $\begin{array}{l}\text { Block- } \\
\text { chain } \\
\text { semesters }\end{array}$ \\
\hline teacher 1 & Female & Telecommunications Engineering & 11 & 2 \\
teacher 2 & Female & Human Resource Management & 20 & 1 \\
teacher 3 & Male & Chinese Language and Literature & 31 & 1 \\
teacher4 & Male & 13 & 1 & \\
teacher5 & Female & 32 & 1 & \\
\hline
\end{tabular}


The other is the course materials shared by teachers voluntarily. These materials include the syllabus, courseware, and course evaluation materials. The researchers used these course materials to learn more about online course design and evaluation based on blockchain and to check for consistency with what was reported in the interviews. The approach of qualitative case studies deals with multiple evidence to converge in a triangulated manner. Courses are used to measure in a triangulated manner and provide information (Merriam, 2009).

\subsection{Data analysis}

The data were analyzed for two interviews and course materials before and after the course began. The interview data were analyzed before the beginning of the course and after the course to establish the relationship between the two. The course material is rich and corroborates the interview information. When trigonometry is used to measure the course materials, it is also necessary to judge whether the interview content and the course materials support each other. The interviews were conducted in an undisturbed environment. In order to prevent mutual influence and pollution, the samples were interviewed one teacher at a time. The interviews were recorded after obtaining the consent of the participants, and then transcribed into six interview transcripts. Using NVivo software to make initial code identification (Merriam, 2009). As new concepts emerge, new code is added, new coding categories are generalized, and an existing list of coding categories is added. Axial coding was performed to block coding and establish a common theme (Merriam, 2009). A constant method of comparison is used in each subject to look for similarities and differences to reduce repetition and optimize data. Discussions were then conducted by the three masters in education to ensure that the data were interpreted accurately and that appropriate changes were made.

\section{Findings}

\subsection{Blockchain-based online course design (TCK)}

Among blockchain-based online course design, teacher 1 adopted the course design method of engineering education when teaching telecommunication engineering, and used the Washington agreement as the basis for capacity-output-oriented design (Bin et al., 2018). The ability index points are designed as three items: "be able to use the knowledge to solve the complex engineering problems in related fields", "be able to analyze the complex engineering problems in related fields through various kinds of knowledge, and get effective conclusions", "be able to use the scientific principles and professional knowledge to memories the complex engineering problems in related fields" (Peter, 2019; Passow \& Passow, 2017). As human resource management is a practical management course, the study draws lessons from the design requirements of engineering education courses using blockchain. Through the discussion of experts, the index point of capability evaluation is designed as four 


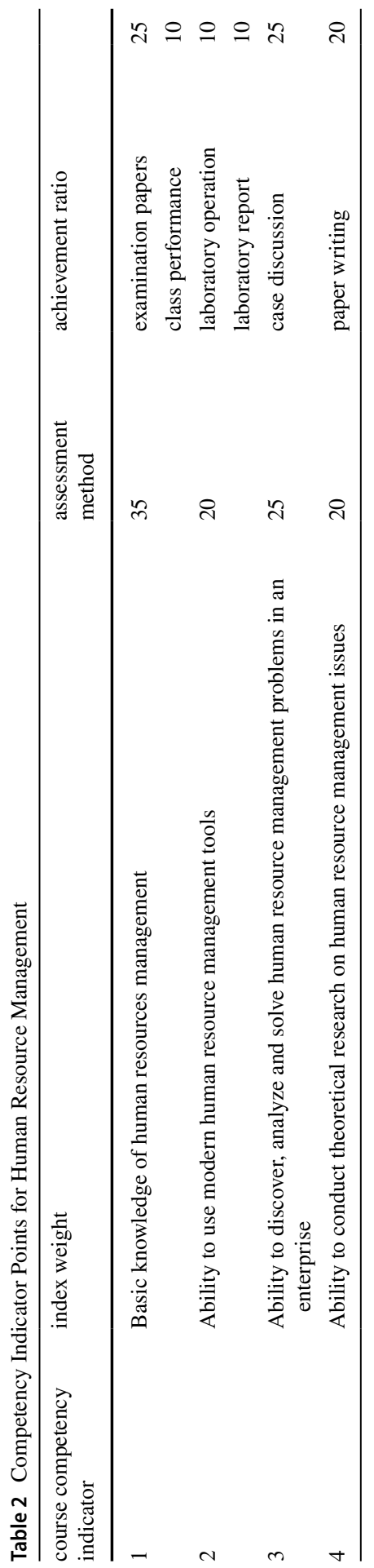


items: the ability to grasp basic knowledge of human resource management, the ability to use modern human resource management tools, the ability to discover, analyze and solve the actual problems of enterprise human resource management, and the ability to research the human resource management problems (See Table 2 for specific indicators and evaluation methods) (Peter, 2019). Teacher 3 supplemented the design of Chinese language and literature in traditional ways, such as adding lecture notes and course assignments. Course evaluations include: class performance scores, course assignments, and final exam scores. The design of teacher 4 of natural resources science is mainly the interactive reform of curriculum content and the immersion design of examination links. Teacher 5 integrated the blockchain with the original experimental platform in the course of teaching.

\subsection{Blockchain adapted to online course design and evaluation (TPK)}

In the application of blockchain, since the use of blockchain is a unified arrangement of colleges and universities, the five teachers approach. The content are mainly data acquisition, data storage and data use.

Teacher 1: “ Input student name, student number, learning ability indicators, assessment methods, scores, the weight of the item, the item scores and other data in the blockchain platform, through the intelligent contract processing into the distributed account book alliance, through the consensus mechanism to verify its data, the evaluation of student score data reached consensus. ". The blockchain then tests the achievement of students' course requirements through quantitative and qualitative analysis, obtains the raw data of students' six evaluation scores, calculates the contract code through the rules, and finally obtains the evaluation of whether the students pass or fail."

Teacher 2 added: "After entering the data, the blockchain will check the data. Once I made a mistake, the blockchain platform will remind me that the data is incorrect compared with other sources, and the status of the contract will be updated after correcting the error. The blockchain is a timely way to correct the error and trace the source."

Teacher 3 introduced: "Because my online courses do not use competency-based indicators, my Chinese language and literature data is still based on classroom performance scores, course assignment scores and final exam results of three inputs, but the blockchain is better than the traditional way of data privacy protection. Looking at student scores previously, students of all kinds of data are open, and one can see a lot of student data. Now a student has a pass code, and it has strong security. In addition, students have their own pass code, and you can check the data to understand their own courses. Employers can also buy pass code to understand a student's course data information. Schools and students can also get some income."

Teacher 4 said, "We combine blockchain with DingTalk to automatically grade and identify classroom performance, interactive assignments, and test results. Using the blockchain's alliance of the distributed ledger, teachers and students can apply for the revision of each grade within a specified period of time, give reasons, be 
reviewed by teachers and academic administrators, and correct errors in accordance with consensus mechanisms and intelligent contracts. It is fair and transparent. Students have a better understanding of how to get better grades and have some say in their own scores. They are highly motivated and more focused on all aspects of their performance."

Teacher 5:"The data input of experimental psychology blockchain is mainly experimental performance and experimental results. These experimental platforms have detailed records and blockchain will be based on a pre-determined consensus and intelligent contract to determine the score of the students. If you want to change the scores of students, it needs to change the whole experimental record, including experimental steps, results and the video record of the experimental process, which is impossible to achieve. This greatly safeguards the fairness. At the same time data rights are well established and if you don't have a pass code, you don't have access to the relevant data of the course to protect multiple rights."

\subsection{Online course design of technological pedagogical content knowledge (TPACK)}

The five teachers' online courses are divided into three stages: pre-class, while class and post-class. Blockchain focuses on the combination of qualitative data and quantitative data, process data and result data, and to trace, weight, analyze data and get multi-trust through machine learning. So teachers pay attention to the process design and evaluation of the course and give full play to the advantages of blockchain. Teacher 1 said: "The pre-class stage includes informing students in groups of the content and requirements of the class, through software to the students to release learning content, including courseware PPT, cases, video learning materials. In the class it is mainly through the live broadcast to explain to the students, because the theory explanation is very important. In addition, telecommunication engineering courses focus on experiments. The course is interspersed with three experiments on the line. Students' theoretical knowledge will also be determined through examination papers."

Teacher 2 said: "human resource management course is a course with strong theory and application. Before the class, we will send students the learning materials of this course, and then explain the learning content in class, and pay more attention to case discussion and experiment. Two case discussions were conducted in the form of leaderless group and randomly grouped to form a case report document as well as writing papers."

Teacher 3 said, "Chinese language and literature is concerned with the mastery of knowledge, the control and use of words, so we focus on the classroom performance, whether to answer questions actively, and the quality of answering questions. The quality of students' interaction with us will also enter the assessment of results, and also avoid the problem of poor quality of students' online lectures. We also focus on students' writing skills, so there will be three course assignments. There will be a final exam at the end of the course. Teachers reported that since it was the first time that blockchain-based online teaching was used, after the course ended, the teaching and research department held a course retake meeting, and the teacher reported on the organization and arrangement of the whole course. The problems will be fully 
discussed with professional teachers, for the implementation of the accumulated experience in the future."

Teacher 4: "Natural resources have theories as well as the observation and design of natural resources. We use blockchain to enhance the immersion of the course. They use blockchain and DingTalk to create interactive links, such as asking students to look at the natural resources around them - soil, trees, even rocks and minerals - that other students can see in sync. The effect is good. On the one hand, there is more content to observe, more diverse to learn, more friendly, more active and more accepting in the classroom, and on the other hand, the blockchain can effectively record these processes as part of process evaluation. For the evaluation of the course learning result, we make a comprehensive evaluation based on the preview, the course learning record and the examination. By the way, some of the questions on the online exam are based on the students' observations in the class. The students take random samples of the exam and the results are very good."

Teacher 5 introduced: "Experimental psychology is a typical and experimental course, which is difficult to learn online. The main work we have done is to integrate blockchain with the existing experimental platform, on which both learning and testing will take place. The learning materials are on this platform, the teacher's explanations are on this platform, and the students' experimental exercises are on this platform. So this platform can not only see all of the student's learning records, but also can analyze where students make more mistakes and which experiments master the problem. On the test, 50 points are devoted to the learning process on the platform, and on the final exam, there is a set of questions for each student based on their learning ability of blockchain machine. The test is for the weak parts, and the results are better."

The course data of each link and skill point of the students are input by the corresponding teachers, laboratories and staff into the blockchain system, and are stored, evaluated and analyzed through the distributed bookkeeping and intelligent contract of the blockchain system. By giving the student a pass code, the student can check his own data and apply for correction.

\subsection{Suggestions on Successful Completion of Online Courses Design and Evaluation Based on Blockchain}

In general, the teachers' suggestions in the discussion are consistent with the coding scheme. There are four main points in the successful design and evaluation of the online course based on blockchain. The first is leadership support. The second is to take the ability appraisal as the course design and the appraisal method, at the same time the experimental course can emphasizes the construction of platform, immersion learning and individualized examination. And the third is the group pattern of the.course research.

\subsection{Leadership support}

All five teachers spoke about the importance of leadership support in their interviews with suggestions for successful research into blockchain-based online courses. 
The reason for this understanding is because in the design and implementation process needs a variety of funds, technology, upstream and downstream support. Leadership support can better promote with more input.

Teacher 1 pointed out: "The course implementation needs certain funds, and it is the leadership to give this course design more financial support to be able to successfully implement. In addition, when I was designing the course, the experimental arrangements were in conflict with other disciplines, and it was the leadership that coordinated the problem."

Teacher 2 said, "We need technical support when we take online courses based on blockchain. The leaders give us a lot of help. Without the support of the leaders, it is very difficult to do this course design."

Teacher 3 thinked the course design is relatively simple, and the final result is not as expected because the leadership is more passive. He said: "the leadership may not understand the blockchain, and they just said to try. It is not too easy to find support when encountered difficulties. So I had to design a relatively simple program, and finally successfully completed the course design, but the effect is not perfect."

Teacher 4 introduced: "During the curriculum reform, we also have some concerns about students' live assignments. We worry that students will lose focus, waste time and affect the progress of the curriculum. The leadership encouraged us to try after we consulted him. Although there are shortcomings, the overall effect is still very good. In particular, we have taken some of the clips and made them into test questions. We have done the immersion test, and we can see that the students have a firmer and more comprehensive knowledge."

Teacher 5 said, "The requirements of the integration technology between blockchain and platform are relatively high, therefore our leadership contact the school's technical staff and external professionals together to do this thing. They have invested a lot in money and technology, and without the support of leadership, this is not going to work."

Why did some leaders strongly support the course and others not so supportive? Different teachers think there are different reasons. Teacher 1 puts forward their leadership support because it is at the stage of the new course design mode that the state requires colleges and universities to explore with new technology, and the research meets the demand of this reform. Teacher 2 thinks it is because he has communicated with the leader 4 times, and the leader realizes the value of this research, and then supports this research with greater efforts. Teacher 3 believes that if the leader has a technical background, the use of new technology will be more supportive. If not aware of the value of technology, support will be less. Teacher 4 believed that their leader, a recent appointee, young and promising, wanted to make a difference, and is willing to reform. Teacher 5 thought that the leader, who majored in psychology, paid more attention to experimental psychology and new technology, so he was willing to support.

\subsection{Based on competency assessment}

The five teachers talked about the effect. The teachers who conducted the competency assessment thought that the course design and assessment based on 
competency assessment matched the blockchain application to achieve better teaching and evaluation results. Teacher 1 shared, "The ability-oriented index points make me pay more attention to the cultivation of students' different ability points in class, and it is easier to find students' weak ability points." Teacher 2 said, "We can examine students' ability points from different angles after class through the combination of the blockchain and the ability evaluation course design. These ability data blockchain can be fully recorded, traced and weight data, and third parties can also be very convenient inquiry. The effect is better." Teacher 3 did not conduct competency-based assessment, "We have no idea how to design the course", he said. "We can only add more types and times to what we have already. The purpose is not clear. Instead, we feel that the data is more and more troublesome. Teachers and students are a little blind and do not feel that they are getting very good results." Teacher 4 said at the time that they hoped to find some points of data recording, which could link the curriculum design, records and assessment. But they did not think of a suitable method, and they improved on the interactive, immersive experience of the course, with blockchain that can transmit data anywhere, anytime, and validate themselves. The effect is good. Teacher 5 believed that for experimental courses, a good platform is very important. So he focused on the technical level and platform integration. The combination of blockchain and experimental platform strengthens the function of the original platform, which is helpful to trace back to the source and record the students' experiments. The machine learning can also be used to examine students' weak links, which is helpful to students' deep unsupervised learning, and the evaluative results can be objective, traceable and self-correcting, thus enhancing students' learning motivation and effect. But he also believed that due to limited personal ability, it was only a technical integration, and he had not done much innovation in the idea of reforming course design suitable for blockchain.

Obviously, the blockchain for improving the teaching effect is worthy of affirmation. However, the emphasis of blockchain improvement is slightly different. The theory and practice courses adopt the index design and evaluation method oriented by ability evaluation, which can make the goal of online course design clear based on blockchain and enhance the advantages of blockchain, which works better. The experiment course is designed with platform, interaction and immersion, and the machine learning ability of blockchain is used to record, trace and correct the experiment process. The index method oriented by ability evaluation can be tried in the design of experimental courses in the future.The index design and evaluation method based on the ability evaluation can make clear the goal of the online course design based on the blockchain, strengthen the advantage of the blockchain, and the effect is better. But whether the liberal art course is suitable such as Chinese language and literature, it also needs to be tailored to the course context. 


\subsection{Research group model}

Among the five teachers, teacher 2 who teaches the online course of Human Resource Management and teacher 4 who teaches Natural Resources has formed the course research group and achieved good results. However, teacher 1,3 and 5 are based on their own exploration, which is more difficult. Teacher 1 said, "although I am a science teacher and have some knowledge of technology, and I decided early on using the competency-based indicator method, it is quite difficult to design and implement all materials by myself, and I have wanted to give up on it several times." Teacher 3 said, "Although I have learned blockchain before, I don't know much about them. Technically, there are a lot of things I don't understand. How to combine them with the course hasn't really come up." Teacher 5 said, "Blockchain and platform integration are difficult, thus I often need to consult professionals. I don't know any questions, and I am sorry that it affects the expansion of some functions."Teacher 2 said: "The research involves the study and application of blockchain technology, the innovative design of Human Resource Management Course, the screening, definition, weight of the index, and course micro-certificate design, etc.. The workload is big and is mostly innovation work. In the course design alone, we designed 6 teaching methods, prepared a large number of teaching materials, recorded 6510-min videos, designed 2 experiments, and did many discussions. Fortunately, the six members of the research team worked together and supported each other." Teacher 4: "Our team has done two things. One is to redesign the content of the course, that is what works online and what works offline, and how the offline content can be transformed into an online format, such as what is made into video clips, what is broadcast live, and what allows students to participate in local interactive presentations. The other is to filter the video or interactive live clips from the course during the exam to improve the effectiveness of the assessment through immersive design, and also to enhance students' motivation and effectiveness in learning. It's a lot of work and it depends on the team working together to get the best results."

It should also be noted that teachers say that the learning and application of blockchain have improved their blockchain level, given them a deeper understanding of new technologies, and enhanced their ability to teach and improve the effectiveness of their lectures.

\section{Discussion}

\subsection{Review of research questions}

As far as research question 1 is concerned, the research shows that the method of course evaluation based on competency-oriented indicators can be considered. by using blockchain to design and evaluate online courses, while designing online courses based on blockchain is aimed at the discipline with strong theoretical and practical operability. For the experimental course, we can consider the integration 
of blockchain and platform, the explanation of immersive and interactive content, and the examination design of machine learning pertinence.We should pay attention to the combination of qualitative and quantitative data, process and result data, and set the weight and proportion reasonably. In the aspect of integrating the pedagogy content knowledge of blockchain technology, teachers have all done the work before, during and after class, and adopted different teaching and evaluation methods according to the characteristics and reality of the subject.

For research question 2, the results of the study provide the following suggestions for teachers who plan to use blockchain in the course design and evaluation: a. The adoption of the technology should be supported by senior leadership. b. To design and evaluate the course from the perspective of competence evaluation, and to record the process and result of the course from multiple angles by using blockchain is helpful to win the trust of many parties and obtain better effect. c. Support each other in a model of research group.

\subsection{Advantages of online course design based on blockchain}

Blockchain helps to build system trust. All five teachers agree that the biggest benefit of blockchain to online course teaching is to improve multi-party trust and build up systematic trust. Teacher 1 said: "since the blockchain can trace the data and ensure the accuracy and comprehensiveness of the data, both students and employers accept the results of the course evaluation." Teacher 2 said: "In the past, students have always come to check the results after the final results, but this year no one check points, and students also trust to support the course results." Teacher 3 shared: "In the past, schools and management have repeatedly stressed the need for teachers to be accurate and fair in their assessment of students. With the use of the blockchain, this requirement is reduced and it is felt to be more objective and accurate." Teacher 4 said, "The blockchain records the learning process of the students, the learning status of the course, the answers and the interactive display. Some data are input by the teachers and some data are directly generated after the standard has been set. The evaluation results are objective and fair and the dispute on the results has been significantly reduced." Teacher 5 said, "There has always been a problem of unclear evaluation criteria for experimental courses. After using blockchain, it has a good evaluation, because all the processes during the experiment is recorded, whether it is instrumental operation record or the video record. Blockchain can also generate experimental report according to students' experimental situation, and everyone was fine with it." It is clear that,the blockchain has increased trust in the quality of the course and evaluation of students' learning.(Amiraullt, 2019; Vu et al., 2019).

After the teaching reform of the online course based on blockchain, the content is more abundant, and the teaching forms are more diverse. The records of the learning process are more detailed. The students' learning interest and attitude have been promoted, and their learning ability has been improved. Teacher 1 points out that she has made adjustments to the teaching methods of the telecommunication engineering course, adding online experiments, videos, flipped classroom and 
other forms, and that students' learning initiative and effort have increased significantly, "I used to have very few students asked me questions after class, but now I often have students contacted me to ask questions after class." Teacher 2 said, "The understanding and application skills of human resource management are important, but students don't value them because it is difficult to assess. But now students know they have to go through a number of tests, each weighted to represent a different competency point, and these results will be seen in the blockchain by future graduate tutors or employers, so students value the learning of various competencies." Teacher 3 shared that the micro certificates of blockchain and the incentives that follow the messages also reinforce students' motivation to learn. Teacher 4 shared that students attach great importance to interactive presentations, which is carefully designed to show teachers and students that their ability to use professional knowledge and language has been greatly improved. Teacher 5 thought that students know that the experiment is well documented and that weak points may be the focus of future exams, so they prepare more carefully and perform better than before. From the above we know the comprehensive ability of the students was improved.

\subsection{Practice of online course design and evaluation based on blockchain}

This study shows that the research of course design and practice is not enough only for teachers, but also for leaders' support. Although teachers are the main users of the blockchain, the support of senior leaders is crucial. Three key factors may influence a leader's support: requirements of the country, the leader's own skill level and the level of communication with the leader. But pay attention to the fact that the leader is supporting, not directing.

It can be seen from the interview results that the division of the labor and mutual support among the members of the research group are very helpful to the successful completion of the research and the teaching reform of the course with the new technology. The effect of group cooperation in complex work is much better than that of individual (Aboramadan et al., 2020). Teachers can get emotional support, technical support and a sense of value and trust from the work of these teams (Lizcano et al., 2020). These complex and creative tasks are difficult for individuals to accomplish, and even then they are limited by their thoughts and abilities to achieve the effect of working together as a team (Spotts, 1999).

This study not only explored the blockchain-based course design and evaluation methods. According to the TPACK research framework, it can be found that it enhances the professional and technical capacity of teachers, and it is of great significance for teachers to apply new technology to improve the teaching quality of professional courses. In this study, the technology development of blockchain is mainly through training and mutual discussion, and after a certain theoretical basis, it is gradually familiar with and uses the technology tools through the practice. In the technical and 
professional content of knowledge, it is mainly through seminars, lectures to achieve progress, and uses the course design ideas of competency assessment indicators-oriented. However, the support in the teaching method is limited, mainly for micro-video, case discussion, experiment and so on, and mainly relying on teachers' own experience and ability. From the TPACK research framework and research practice, professional and technical training on the one hand depends on the form of speaking to obtain theoretical knowledge, but more importantly through the members of each other to discuss, practice, combine with the teaching model, and links between subject matter and pedagogy to solve practical problems.

\subsection{The deficiency of this research and the prospect of the future research}

The limitations of this study are twofold: The first limitation is that the study is involved only one school, five courses, and teachers from the same university, all interacting with each other in the course study, therefore many feelings and perceptions are similar, and the homology error is inevitable. Another limitation is that only interviews and course materials are used for data collection. Future research will be complemented by more data sources that can be triangulated, such as classroom observations and in-depth interviews with students and administrators.

\subsubsection{Future research will be oriented in two directions}

First, it has to do with the characteristics of the subject. This study shows that the blockchain has a good effect on the course design by adopting the method of competence-oriented index evaluation in the discipline that pays equal attention to both theory and practice. Experimental courses based on platform construction, interactive and immersive curriculum design have a good effect. However, it is not clear whether blockchain will have different requirements on the course design in other professional courses. Fedorova and Skobleva (2020) consider that blockchain cannot fully reflect the differences and advantages between blockchain and traditional course management for courses with less data, the single mode of class and evaluation based mainly on final results. Therefore, whether blockchain technology is suitable for all disciplines, and how to choose different teaching design and evaluation methods of online courses adapted to blockchain according to the characteristics of disciplines, is worth studying and discussing.

The second relates to the research promotion. It is found that the teachers are not active in the research and practice of course reform, and the process of course reform is time-consuming, slow and difficult to obtain support (Spotts, 1999). Therefore, if we want to advance the teaching reform, the leaders must provide the opportunity and the support to the teachers, to carry on the course research by the research team. Future research will also focus on how the reward system 
should be designed and how it affects teachers' motivation, initiative and mutual assistance.

\section{Conclusion}

This research shows that blockchain-based online course design is suitable to use a variety of teaching methods to obtain qualitative and quantitative process-based and outcome-based data, win the trust of multiple parties and enhance students' learning effectiveness. Specifically, for the discipline with strong theory and practice, we can take the index-oriented method of competence evaluation into consideration, adopt the form of research group, obtain the leadership support, and get better online course design and evaluation effect.

Finally, we also address several deficiencies: the first is the limited source of data and sample size. Secondly, although it is considered that the abilityoriented index method is more effective in the course design, there are great differences in different subjects and course requirements. Perhaps not all disciplines are suitable for this approach. The experimental course mainly stays at the technical level, such as improving the platform and adopting some techniques, but how to unify the teaching content, course design and course evaluation in one frame has not been well tried.The future scholars pay attention to different disciplines for different blockchain-based online course design and evaluation methods.

\section{Appendix 1}

Table 3 Detailed interviewing questions (the first stage)

Interviewing questions

TPACK

frame-

work

1.What do you know about blockchain?

TK

2.Do you think blockchain application in online course design can improve teaching quality? TK

3.If you think you can improve the quality of your online education, what can you do to TPK improve it?

4. What do you expect to be the main difficulties in designing blockchain-based online courses?

" $\mathrm{T}$ " is labeled as blockchain, which could be viewed as a technological innovation 


\section{Appendix 2}

Table 4 Detailed interviewing questions (the second stage)

\begin{tabular}{|c|c|}
\hline Interviewing questions & TPACK framework \\
\hline 1.How do you design and evaluate online courses based on blockchain? & TPK \\
\hline 2. What adjustments have you made? & TPACK \\
\hline $\begin{array}{l}\text { 3. What do you think are the main advantages of blockchain-based online course } \\
\text { design and evaluation? }\end{array}$ & TCK \\
\hline $\begin{array}{l}\text { 4.Do you think the learning and application of blockchain has improved your block- } \\
\text { chain level and helped your teaching ability? }\end{array}$ & TCK \\
\hline $\begin{array}{l}\text { 5. What are your suggestions for future research on blockchain-based course } \\
\text { design? }\end{array}$ & TPACK \\
\hline
\end{tabular}

" $\mathrm{T}$ " is labeled as blockchain, which could be viewed as a technological innovation

Acknowledgements The authors want to thank to the teachers and students enrolled in this study. And thank the Business School of Henan University for administrative support.

Author Contributions All authors have read and agreed to the published version of the manuscript.

Funding This research was funded by the National Social Science Fund of China, grant number 20BJY215 'Research on Early Warning and Classified Governance of Local Government Hidden Debt Based on Blockchain'. The views expressed in this paper are not necessarily the views of that organization.

To be used for all articles, including articles with biological applications.

\section{Declarations}

Conflicts of Interest The authors declare no conflicts of interest.

Open Access This article is licensed under a Creative Commons Attribution 4.0 International License, which permits use, sharing, adaptation, distribution and reproduction in any medium or format, as long as you give appropriate credit to the original author(s) and the source, provide a link to the Creative Commons licence, and indicate if changes were made. The images or other third party material in this article are included in the article's Creative Commons licence, unless indicated otherwise in a credit line to the material. If material is not included in the article's Creative Commons licence and your intended use is not permitted by statutory regulation or exceeds the permitted use, you will need to obtain permission directly from the copyright holder. To view a copy of this licence, visit http://creativecommons.org/licen ses/by/4.0/.

\section{References}

Aboramadan, M., Albashiti, B., \& Alharazin, H. (2020). Human Resources Management Practices and Organizational Commitment in Higher Education: The Mediating Role of Work Engagement. International Journal of Educational Management., 01, 154-174. https://doi.org/10.1108/ IJEM-04-2019-0160

Amiraullt, R. J. (2019). The Next Great Educational Technology Debate: Personal Data, Its Ownership, and Privacy. Quarterly Review of Distance Education, 02, 55-70. 
Aslan, B., \& Ataşen, K. (2020). A blockchain based lifelong learning platform: The Smart University. MANAS Journal of Engineering., 8(02), 151-154.

Bin, D., Tao, Li., Yi, K., \& Xiangxiang, X. (2018). Block chain design for engineering education learning outcomes. Computer Engineering and Science, 11, 103-108.

Chen, Z. (2019). Re-examination of a Bioinformatics Database Course: Engaging Blockchain Technology. Procedia Computer Science., 162(01), 368-374. https://doi.org/10.1016/j.procs.2019.11.297

Chen, G., Xu, B., Lu, M., et al. (2018). Exploring blockchain technology and its potential applications for education. Smart Learning Environments., 05, 1-10. https://doi.org/10.1186/s40561-017-0050-x

Churchill, D., \& Churchill, N. (2008). Educational affordances of PDAs: A study of a teacher's exploration of this technology. Computer \& Education, 50(4), 1439-1450. https://doi.org/10.1016/j.compe du.2007.01.002

Cox, S., \& Graham, C. R. (2009). Diagramming TPACK in practice: Using an elaborated model of the TPACK framework to analyze and depict teacher knowledge. TechTrends, 53(5), 60-69. https://doi. org/10.1007/s11528-009-0327-1

Don, T., Alex T. (2016). Blockchain Revolution: How the Technology Behind Bitcoin is Changing Money, Business, and the World. Portfolio Press

Downes, S. (2019). Recognising Achievement with Badges and Blockchain in a Connectivist MOOC. Journal of Learning for Development., 06(03), 273-286.

Fedorova, E. P., \& Skobleva, E. I. (2020). Application of Blockchain Technology in Higher Education. European Journal of Contemporary Education, 03, 552-571. https://doi.org/10.13187/ejced.2020.3. 552

Graham, C. R. (2011). Theoretical considerations for understanding technological pedagogical content knowledge (TPACK). Computers \& Education., 57(03), 1953-1960.

Guiyi, H. (2021). Research on the Learning Outcome Authentication Management System based on the Blockchain Technology. Modern Educational Technology, 03, 69-75.

Jirgensons, M., \& Kapenieks, J. (2018). Blockchain and the Future of Digital Learning Credential Assessment and Management. Journal of Teacher Education for Sustainability, 01, 145-156. https://doi. org/10.2478/jtes-2018-0009

Karatas, E. (2018). Developing Ethereum Blockchain-Based Document Verification Smart Contract for Moodle Learning Management System. Online Submission International Journal of Informatics Technologies, 04, 399-406. https://doi.org/10.17671/gazibtd.452686

King, L. G., McKim, A. J., \& Raven, M. R. (2019). New and Emerging Technologies: Teacher Needs, Adoption, Methods, and Student Engagement. Journal of Agricultural Education, 03, 277-290. https://doi.org/10.5032/jae.2019.03277

Koehler, M. J., Shin, T. S., \& Mishra, P.(2011). How Do We Measure TPACK? Let Me Count the Ways. Educational Technology, Teacher Knowledge, and Classroom Impact: A Research Handbook on Frameworks and Approaches, IGI Global. https://doi.org/10.4018/978-1-60960-750-0.ch002

Koehler, M. J., \& Mishra, P. (2009). What is technological pedagogical content knowledge? Contemporary Issues in Technology and Teacher Education, 9(1), 60-70.

Kong, X., Liu, N. J., \& Zhang, M. H. (2021). Analysis of online teaching data before and after the COVID-19 epidemic. Journal of Tsinghua University (Science and Technology)., 02, 104-116. https://doi.org/10.16511/j.cnki.qhdxxb.2020.21.017

Kontzinos, C., Karakolis, V., \& Skalidakis, S. (2020). CombiningBlockchain, Semantics And Data Analytics for University Process Optimisation. International Journal on Computer Science and Information Systems, 14(02), 59-77.

Lee, S. (1986). Those who understand: Knowledge growth in teaching. Educational, Researcher, 15(7), 4-14. https://doi.org/10.2307/1175860

Lemieux, VL., Rowell, C., Seidel, M. (2020) Caught in the middle?: Strategic information governance disruptions in the era of blockchain and distributed trust. Records Management Journal,20(04). https://doi.org/10.1108/RMJ-09-2019-0048

Li, X., Yang, X. (2018). Using blockchain technology to create a new ecology of OER. Distance Education in China.06,58-67+80. https://doi.org/10.13541/j.cnki. chinade.20180611.005

Li, D., Yang, X., Zhang, H., Wang Y. (2017) .Study of Relationship between Pre-Service Information Technology Teacher and TPACK.International Conference of Educational Innovation through Technology (EITT).47-55. https://doi.org/10.1109/eitt.2017.19 
Li, Q., \& Zhang, X. (2017). Blockchain: A Technology to Win Open and Trust in Education. Journal of Distance Education, 01, 36-44. https://doi.org/10.15881/j.cnki.cn33-1304/g4.2017.01.004

Lizcano, D., Lara, J. A., \& White, B. (2020). Blockchain-Based Approach to Create a Model of Trust in Open and Ubiquitous Higher Education. Journal of Computing in Higher Education, 01, 109-134.

Long, T., Cummins, J., \& Waugh, M. (2019). To flip or not in higher education: A tale of three instructors. Asian-Pacific Journal of Educational Researcher, 29(1), 124-136. https://doi.org/10.1007/ s40299-019-00470-4

Mentzer, K., Frydenberg, M., \& Yates, D. J. (2020). Teaching Applications and Implications of Blockchain via Project-Based Learning: A Case Study. Information Systems Education Journal, 06, 57-85.

Merriam, S. (2009). Qualitative research: A guide to design and implementation. Jossey-Bass.

Milovich, M. J. R., Nicholson, J. A., \& Nicholson, D. B. (2020). Teaching Tip: Applied Learning of Emerging Technology: Using Business-Relevant Examples of Blockchain. Journal of Information Systems Education, 03, 187-195.

Mishra, P., \& Koehler, M. J. (2006). Technological pedagogical content knowledge: A framework for teacher knowledge. Teacher College Record, 108(6), 1017-1054. https://doi.org/10.1111/j.14679620.2006.00684.x

Moubarak, J., Filiol, E., Chamoun, M. (2018) On blockchain security and relevant attacks, 2018 IEEE Middle East and North Africa Communications Conference (MENACOMM). https://doi.org/10. 1109/MENACOMM.2018.8371010

Niess, M. L. (2011). Investigating TPACK: Knowledge Growth in Teaching with Technology. Journal of Educational Computing Research, 44(3), 299-317. https://doi.org/10.2190/EC.44.3.c

Oganda, FP.. et al.(2020) Blockchain Education Smart Courses of Massive Online Open Course Using Business Model Canvas. 2020 2nd International Conference on Cybernetics and Intelligent System (ICORIS). https://doi.org/10.1109/ICORIS50180.2020.9320789

Pablo, R. V., \& Carles, L. S. (2019). Blockchain in the University: A Digital Technology to Design, Implement and Manage Global Learning Itineraries. Digital Education Review., 35, 130-150. https://doi.org/10.1344/der.2019.35.130-150

Passow, H. J., \& Passow, C. H. (2017). What Competencies Should Undergraduate Engineering Programs Emphasize? A Systematic Review. Journal of Engineering Education., 03, 475-526. https://doi.org/ $10.1002 /$ jee.20171

Patton, M. Q. (2002). Qualitative research and evaluation methods (3rd ed.). Sage.

Peter, W. (2019). Does Competency-Based Education with Blockchain Signal a New Mission for Universities? Journal of Higher Education Policy and Management, 01, 104-117. https://doi.org/10.1080/1360080X. 2018.1520491

Petersen, C., \& Hossein, N. (2016). Project-Based Learning through the Eyes of Teachers and Students in Adult ESL Classrooms. Canadian Modern Language Review., 01, 13-39. https://doi.org/10.3138/ cmlr.2096

Pierson, M. E. (2001). Technology Integration Practice as a Function of Pedagogical Expertise. Journal of Research on Computing in Education, 33(4), 413-430.

Punch, K. F. (2005). Introduction to social research: Quantitative and qualitative approaches. Sage.

Raimundo, R., \& Rosário, A. (2021). Blockchain system in the higher education. European Journal of Investigation in Health, Psychology and Education, 11(1), 276-293. https://doi.org/10.3390/ejihp e11010021

Spotts, T. (1999). Discriminating factors in faculty use of instructional technology in higher education. Educational Technology \& Society, 2(4), 92-99.

Vu, P., Adkins, M., \& Henderson, S. (2019). Aware, but Don't Really Care: Student Perspectives on Privacy and Data Collection in Online Courses. Journal of Open, Flexible and Distance Learning., 02, 42-51.

Wang, P., Ting, M. et al. (2020). Investigation and Research on Online Teaching in Middle Schools During the Epidemic. Digital Teaching in Primary and Secondary Schools,(03),66-69. CNKI:SUN:ZSZJ.0.2020-03-019

Wang, P., \& Qiao, S. (2020). Emerging Applications of Blockchain Technology on a Virtual Platform for English Teaching and Learning. Wireless Communications and Mobile Computing, 2020(02), 1-10. https://doi.org/10.1155/2020/6623466

Wu, X. (2020). Research on English Online Education Platform Based on Genetic Algorithm and Blockchain Technology. Wireless Communications and Mobile Computing, 11(09), 1-7. https://doi.org/ $10.1155 / 2020 / 8827084$ 
Wu, Y. (2020).Ministry of Education: It is no longer possible and should not return to the state of teaching and learning before the Covid-19 outbreak[EB/OL]. https://www.sohu. com/a/395412670_161795,2020-05-15/2020-12-13

Xia, H., \& Xu, Q. (2020). Learning record sharing account book construction with Hyperledger Fabric technology. Modern Electronics Technique, 02, 80-83. https://doi.org/10.16652/j.issn.1004-373x. 2020.02.022

Xu, T. (2017). Research on the Development and Significance of "Blockchain+" Education. Journal of Distance Education., 03, 19-28. https://doi.org/10.15881/j.cnki.cn33-1304/g4.2017.02.003

Publisher's note Springer Nature remains neutral with regard to jurisdictional claims in published maps and institutional affiliations. 